\title{
Metabolism Studies of Desvenlafaxine
}

\author{
William DeMaio', Cecelia P. Kane ${ }^{1}$, Alice I. Nichols ${ }^{2 *}$ and Ronald Jordan ${ }^{1}$
}

${ }^{1}$ Formerly of Pfizer Inc, Collegeville, Pennsylvania, USA

${ }^{2}$ Pfizer Inc, formerly Wyeth Research, Collegeville, Pennsylvania, USA

\begin{abstract}
Background: This series of experiments was conducted to describe the metabolic profile of the serotoninnorepinephrine reuptake inhibitor desvenlafaxine (administered as desvenlafaxine succinate) using animal and human models.

Methods: In vivo and in vitro experiments were conducted with humans and preclinical species (CD-1 mice Sprague Dawley rats, and beagle dogs). Single oral doses of $\left[{ }^{14} \mathrm{C}\right]$-desvenlafaxine were administered to each preclinical species for analyses of desvenlafaxine concentration in plasma, urine, and feces. Rats also were subjected to whole body autoradiography and quantitative tissue sampling. The major UDP-glucuronosyltransferase (UGT) isoforms involved in the formation of desvenlafaxine-O-glucuronide were also assessed. In vivo human experiments were conducted with healthy volunteers administered desvenlafaxine 100,300, or $600 \mathrm{mg}$, followed by 72 hours of plasma sampling. In vitro experiments were conducted with human and animal liver microsomes and human hepatocytes to determine the effect of desvenlafaxine on cytochrome P450 (CYP) enzyme activity. Desvenlafaxine concentrations were measured using high performance liquid chromatography and liquid chromatography/mass spectrometry methods.
\end{abstract}

Results: The primary metabolic pathways for desvenlafaxine included glucuronidation, oxidation, and $\mathrm{N}$-demethylation. In humans, desvenlafaxine was the predominant drug-related species in plasma and urine. However, in mice, rats, and dogs, desvenlafaxine-O-glucuronide was the most commonly detected in plasma and urine. Urine was the primary route of excretion of desvenlafaxine in all species. Multiple UGTs were capable of desvenlafaxine metabolism. Oxidative metabolism via the CYP3A4 was a minor contributor to desvenlafaxine metabolism; however, desvenlafaxine did not induce or inhibit CYP3A4 activity. Desvenlafaxine did not act as a significant mechanism-based inhibitor of the assessed CYP isoenzymes.

Conclusion: These findings support other study results suggesting that desvenlafaxine has a simple metabolic profile. Desvenlafaxine is unlikely to contribute to clinically significant CYP-mediated drug-drug interactions. The relatively simple metabolic profile of desvenlafaxine may lead to clinical benefits in those patients being treated for major depressive disorder.

Keywords: Desvenlafaxine; Cytochrome P450; Drug metabolism; Drug-Drug interactions; Major depressive disorder

Abbreviations: AEs: Adverse Events; CYP: Cytochrome P450; DDIs: Drug-Drug Interactions; HPLC: High Performance Liquid Chromatography; LC/MS:LiquidChromatography/MassSpectrometry; MDD: Major Depressive Disorder; NADPH: Nicotinamide Adenine Dinucleotide Phosphate-oxidase; SNRI: Serotonin-Norepinephrine Reuptake Inhibitor; UGT: UDP-Glucuronosyltransferase; UV: Ultraviolet

\section{Introduction}

Major depressive disorder (MDD) is a chronic, disabling illness that affects a substantial proportion of the population [1]. Despite a number of available antidepressants, response and remission rates in patients with MDD remain low, relapse is common, and many patients face a chronic struggle with the burden of depressive illness [2]. Even in the Sequenced Treatment Alternatives to Relieve Depression study, in which patient adherence and clinical status were closely followed in a real-world setting, approximately $53 \%$ of patients did not respond to an adequate trial of a first-line selective serotonin reuptake inhibitor and only $28 \%$ reached remission [3]. The less-than-adequate rates of successful treatment in patients with MDD can be attributed to multiple factors, including the tolerability of the antidepressant treatment, particularly if the medications have a high risk for drugdrug interactions (DDIs) [4].
The serotonin-norepinephrine reuptake inhibitor (SNRI) desvenlafaxine (administered as desvenlafaxine succinate) was approved for the treatment of MDD in 2008 and is in clinical development for the treatment of vasomotor symptoms associated with menopause [5-9]. Desvenlafaxine is administered clinically as an orally active succinate salt formulated as an extended-release tablet for once-daily administration; the free base of desvenlafaxine is also referred to as $O$-desmethylvenlafaxine (ODV) $[6,10,11]$. The efficacy of desvenlafaxine $50 \mathrm{mg} / \mathrm{d}$ in the treatment of MDD has been established in 3 randomized, controlled clinical studies [12-14]. A pooled analysis of data from all 3 trials $(\mathrm{N}=1388)$ demonstrated a significant improvement in all primary and secondary efficacy outcomes with 50and $100-\mathrm{mg} / \mathrm{d}$ desvenlafaxine doses compared with placebo $(P<0.001)$ [14]. In addition, desvenlafaxine $50 \mathrm{mg} / \mathrm{d}$ has a relatively favorable safety profile, with adverse events (AEs) generally considered mild to

*Corresponding author: Alice I. Nichols, PhD, Senior Director, Clinical Pharmacology, Primary Care, Pfizer Inc, formerly Wyeth Research, 500 Arcola Road, Collegeville, PA 19426, USA, Tel: (484) 865-8741; E-mail: alice.nichols@ pfizer.com

Received June 15, 2011; Accepted July 28, 2011; Published July 30, 2011

Citation: DeMaio W, Kane CP, Nichols Al, Jordan R (2011) Metabolism Studies of Desvenlafaxine. J Bioequiv Availab 3: 151-160. doi:10.4172/jbb.1000076

Copyright: (C) 2011 DeMaio W, et al. This is an open-access article distributed under the terms of the Creative Commons Attribution License, which permits unrestricted use, distribution, and reproduction in any medium, provided the original author and source are credited. 
moderate, and rates of discontinuation due to AEs comparable with those of placebo [12-14].

Desvenlafaxine is the major active metabolite of the SNRI venlafaxine [11], and like venlafaxine, desvenlafaxine primarily inhibits the reuptake of serotonin and norepinephrine, with little inhibition of dopamine reuptake [10]. Venlafaxine is metabolized primarily to ODV in humans by cytochrome P450 (CYP) 2D6 (CYP2D6) [15]. In contrast, results from clinical studies indicate that desvenlafaxine is mainly eliminated unchanged by renal excretion, and to a lesser extent metabolized by phase II enzymes to form desvenlafaxine-Oglucuronide and phase I enzymes to form $N, O$-didesmethylvenlafaxine (NODV) [16]. The objectives of this investigation were to assess the metabolism of desvenlafaxine in vitro and In vivo, and to explore the implications of the metabolic profile of desvenlafaxine on the potential for certain drug-drug interactions with its clinical use.

\section{Materials and Methods}

\section{Materials}

Desvenlafaxine succinate, venlafaxine hydrochloride, $\mathrm{N}, \mathrm{O}$ didesmethyl desvenlafaxine (NODV), and midazolam maleate were synthesized or obtained from Pfizer Inc, formerly Wyeth Research (Princeton, NJ). Radiolabeled $\left[{ }^{14} \mathrm{C}\right]$-desvenlafaxine was supplied by Amersham Biosciences (Buckinghamshire, UK). Solvents used for preparation of oral dosing solutions, extraction, and for chromatographic analysis were of high performance liquid chromatography (HPLC) or reagent grade and were purchased from EMD Chemicals (Gibbstown, NJ). Methylcellulose, nicotinamide adenine dinucleotide phosphate (NADPH)-oxidase, $\boldsymbol{\alpha}$-napthoflavone, coumarin, quinidine, diethyldithiocarbamate, ketoconazole, benzylimidazole, taxol, diclofenac, 8-methoxypsoralen, quercetin, tranylcypromine, ethoxyresorufin, dextromethorphan, $p$-nitrophenol, components for the NADPH regenerating system (nicotinamide adenine dinucleotide phosphate [NADP ${ }^{+}$], D-glucose-6-phosphate, glucose-6phosphate dehydrogenase), and uridine $5^{\prime}$-diphosphoglucuronic acid triammonium salt (UDPGA) were purchased from Sigma-Aldrich (St. Louis, MO) or Gentest Corporation (Woburn, MA). Resorufin, ethoxyresorufin, and dextrorphan were purchased from Molecular Probes, Inc. (Eugene, OR). Sulfaphenazole, $\mathrm{S}(+)$-mephenytoin, and dextrorphan were obtained from Ultrafine Chemicals (Manchester, UK). 4'-hydroxy-S-mephenytoin, 4'-hydroxymephenytoin, bufuralol hydrochloride salt, 1'-hydroxybufuralol, 1'-hydroxymidazolam, 6a-hydroxytaxol, 6a-hydroxypaclitaxel, 7-hydroxycoumarin, paclitaxel, and 4'-hydroxydiclofenac were obtained from BD Biosciences (San Jose, CA). Cryopreserved human hepatocytes, hepatocyte suspension media, hepatocyte culture media, and liver microsomes from male Sprague Dawley ${ }^{\mathbb{R}}$ rats, male CD-1 mice, and male beagle dogs were obtained from Celsis In Vitro Technologies (Baltimore, MD). The cDNA-expressed human CYPs in Escherichia coli membranes were prepared in-house from constructs obtained from the LINK industrial consortium [17]. Human liver microsomes were received from either a characterized microsome bank or prepared in-house from human livers obtained from the International Institute for the Advancement of Medicine (Exton, PA). Control human plasma, with ethylenediaminetetraacetic acid as an anticoagulant, was purchased from Biological Specialty Group (Colmar, PA).

\section{In vitro incubations}

Human and animal liver microsomes were prepared by differential ultracentrifugation utilizing the method described by Lake [18] with slight modifications, and microsomal protein and CYP content were determined by the methods of Bradford [19] and Omura and Sato [20], respectively. Microsome aliquots of 500 to $1000 \mu \mathrm{L}$ were stored frozen at $-80^{\circ} \mathrm{C}$ until use.

Microsomal incubations contained desvenlafaxine (final concentration ranging from 10 to $300 \mu \mathrm{M}), 10-\mathrm{mM}$ magnesium chloride, and 1-mg/mL liver microsomes in $0.1-\mathrm{M}$ sodium/potassium phosphate buffer, $\mathrm{pH} 7.4$. Aliquots were dissolved in $0.25 \%$ polysorbate 80 and $0.5 \%$ methylcellulose in water, or in methanol, evaporated to dryness with nitrogen, and redissolved in phosphate buffer containing $\mathrm{MgCl}_{2}$. Samples were incubated for 5 minutes at $37^{\circ} \mathrm{C}$, and reactions were initiated by the addition of UDPGA and/or an NADPH regenerating system. Reactions were stopped by the addition of ice-cold acetonitrile, and denatured protein was separated by centrifugation at $1500 \times g$ for 10 minutes at $4^{\circ} \mathrm{C}$ (Model T21 super centrifuge, Sorvall). The supernatant was evaporated to dryness, redissolved in water/acetonitrile (90:10, v:v), and samples were analyzed by HPLC with ultraviolet (UV) detection and liquid chromatography/mass spectrometry (LC/MS).

Incubation mixtures for cDNA studies were prepared utilizing LINK enzyme membranes from $E$ coli cells transfected with various cDNAs, each expressing a specific human liver CYP enzyme. The CYP concentration was kept constant (500 nM of each cDNA). Reactions were initiated by the addition of an NADPH regenerating system. The protein was then precipitated by the addition of acetonitrile with 1-mM dextrorphan added as an internal standard. Samples were shaken for 10 minutes, centrifuged, and the supernatant was analyzed by LC/MS.

Cryopreserved human hepatocytes were thawed at $37^{\circ} \mathrm{C}$ and hepatocytes suspensions were transferred to $50-\mathrm{mL}$ beakers on ice. Cold hepatocyte suspension media was added to each suspension, with gentle shaking to prevent cells from settling. Cell suspensions were centrifuged at $100 \times g$ for 3 minutes at $4^{\circ} \mathrm{C}$ (Model T21 super centrifuge, Sorvall), and pellets were resuspended in $5 \mathrm{~mL}$ of cold hepatocyte culture media. Cell suspensions contained $\sim 6 \times 10^{5}$ viable hepatocytes/ $\mathrm{mL}$ and an average viability of $77 \%$. Desvenlafaxine was added to cell suspensions in 12-well plates at a final concentration of $300 \mu \mathrm{M}$; midazolam $10 \mu \mathrm{M}$ was included as a positive control to confirm the hepatocytes were metabolically active. All incubations were conducted at $37^{\circ} \mathrm{C}$ for 4 hours in an incubator supplied with $5 \% \mathrm{CO}_{2}$. Suspensions were then sonicated with $200-\mu \mathrm{L}$ methanol, acetonitrile was added to each sample, and denatured protein was separated by centrifugation at $2000 \mathrm{rpm}$ for 5 minutes at $4^{\circ} \mathrm{C}$. The supernatant was evaporated, reconstituted, and samples were analyzed by HPLC/UV and LC/MS.

The UDP-glucuronosyltransferase (UGT) isoforms involved in formation of desvenlafaxine-O-glucuronide were identified by incubating $100-\mu \mathrm{M}\left[{ }^{14} \mathrm{C}\right]$-desvenlafaxine with UDPGA in human liver microsomes and in UGT Supersomes (ie, baculovirus infected insect cells expressing human UGTs) at $37^{\circ} \mathrm{C}$ for 2 hours. In addition, p-nitrophenol $(50 \mu \mathrm{M})$ was incubated with human liver microsomes (1$\mathrm{mg}$ protein $/ \mathrm{mL}$ ) as a positive control for UGT enzyme activity. Samples were then extracted with $5 \mathrm{~mL}$ of methanol, vortex mixed, sonicated, and centrifuged at $3000 \times g$ for 15 minutes at $4^{\circ} \mathrm{C}$. Supernatants were then evaporated; reconstituted in $300 \mu \mathrm{L}$ of methanol/10 mM ammonium acetate, $\mathrm{pH} 3.5(6 / 4, \mathrm{v} / \mathrm{v})$; followed by HPLC/UV analysis with radioactivity flow detection and LC/MS. Recovery of radioactivity was determined using a Packard Tri-Carb Model 3100TR liquid scintillation spectrometer (PerkinElmer, Waltham, MA) and $5 \mathrm{~mL}$ of Ultima Gold"'scintillant. 


\section{Dosing of animals and collection of samples}

Preclinical species were administered a single, oral dose of $\left[{ }^{14} \mathrm{C}\right]-$ desvenlafaxine by gavage of aqueous solutions at the following target doses: male beagle dog, $30 \mathrm{mg} / \mathrm{kg}(10 \mathrm{mg} / \mathrm{mL}, 3 \mathrm{~mL} / \mathrm{kg}, 30 \mu \mathrm{Ci} / \mathrm{kg})$; Sprague Dawley rat, $30 \mathrm{mg} / \mathrm{kg}(3.0 \mathrm{mg} / \mathrm{mL}, 10 \mathrm{~mL} / \mathrm{kg}, 50 \mu \mathrm{Ci} / \mathrm{kg})$; and CD-1 mouse, $30 \mathrm{mg} / \mathrm{kg}(3 \mathrm{mg} / \mathrm{mL}, 16.7 \mu \mathrm{Ci} / \mathrm{mg}, 50 \mu \mathrm{Ci} / \mathrm{mL})$. The oral dosing solution was prepared by combining $\left[{ }^{14} \mathrm{C}\right]$-desvenlafaxine and unlabeled desvenlafaxine in a solution of $0.25 \%$ polysorbate 80 and $0.5 \%$ methylcellulose in distilled water.

Whole blood (approximately $0.8,5$, or $10 \mathrm{~mL}$ ) from preclinical species was collected into heparinized tubes at 1, 4, 8, and 24 hours postdose for male beagle dogs, male rats, and male mice, and 1 and 8 hours for female rats. Plasma was obtained by centrifugation at $4^{\circ} \mathrm{C}$ within 2 hours of blood collection. Triplicate aliquots of whole blood $(200 \mu \mathrm{L})$ were placed into combusto-cones (PerkinElmer) for combustion, allowed to air dry, oxidized, and analyzed for radioactivity content.

Urine and feces from preclinical species were collected separately, with urine collected on dry ice from 0 to 8 and 8 to 24 hours in dogs and male rats, 0 to 8 hours in female rats, 0 to 24 hours in male mice. Except for female rats, feces were collected at room temperature from 0 to 24 hours. Fecal samples were homogenized in $\sim 5$ volumes $(\mathrm{v} / \mathrm{w})$ of water, and aliquots of $\sim 0.2$ to $0.4 \mathrm{~g}$ of the homogenate were subjected to combustion, weighed, and allowed to air dry. The samples were then oxidized and radioactivity content was determined.

For the determination of the mass balance of $\left[{ }^{14} \mathrm{C}\right]$-desvenlafaxine following oral administration, urine and feces from preclinical species were collected in a similar manner as described above from 0 to 24 hours in male rats, male mice, and male dogs, every 24 hours from 24 to 120 hours in male rats, and from 24 to 168 hours in dogs. Feces and cage rinse were collected at room temperature at 24-hour intervals until 7 days postdose. To collect cage rinses, cages were rinsed with a solution of warm water/ethanol $(70: 30, \mathrm{v} / \mathrm{v})$, swabbed with gauze pads to recover residual radioactivity, gauze pads were rinsed with water/ ethanol $(70: 30, \mathrm{v} / \mathrm{v})$, and the rinse was collected for analysis.

The tissue distribution of $\left[{ }^{14} \mathrm{C}\right]$-desvenlafaxine-derived radioactivity following a single, oral administration of $30 \mathrm{mg} / \mathrm{kg}$ to Sprague Dawley rats was determined using quantitative whole body autoradiography and quantitative tissue dissection. One Sprague Dawley rat was sacrificed per time point after dosing. At $0.5,4,8,24,48$, and 120 hours after dosing, blood and other selected tissues (ie, bone, brain, fat, large intestine, liver, prostate, small intestine, stomach, and urinary bladder) were removed. Blood was collected by cardiac puncture into a heparinized syringe an d separated to retain a whole blood sample and to harvest a plasma sample by centrifugation. After dissection, most tissues were weighed and homogenized (Polytron mechanical homogenizer) in approximately 3 volumes of water. Approximately $0.2 \mathrm{~g}$ of the homogenates, in duplicate, was analyzed after combustion to determine the concentration of radioactivity.

\section{Dosing of humans and collection of samples}

In studies of desvenlafaxine metabolism in humans, healthy adult volunteers 18 to 45 years of age received a single oral dose of desvenlafaxine 100,300 , or $600 \mathrm{mg}$ on days 1,5 , and 9 of a 12-day study. The order for administrations of doses of desvenlafaxine was randomized. Plasma samples for determination of desvenlafaxine concentrations were collected up to 72 hours following oral administration. Urine and blood samples were collected as described elsewhere [16]. Selected samples were analyzed for metabolite profiles [16].

\section{Quantitative analysis of desvenlafaxine in serum or plasma samples}

Concentrations of desvenlafaxinein human plasma were determined as described elsewhere using HPLC with fluorescence detection [16]. Concentrations of unconjugated and total desvenlafaxine and NODV in human urine were assessed by HPLC with UV detection [16].

\section{Determination of radioactivity and processing of samples for profiling and metabolite identification by LC/MS}

To evaluate the total radioactivity of $\left[{ }^{14} \mathrm{C}\right]$-desvenlafaxine in blood samples and fecal homogenates, samples were oxidized in a Model 307 Tri-Carb sample oxidizer, equipped with an Oximate-80 Robotic Automatic Sampler (PerkinElmer), using Carbosorb ${ }^{\circledR}$ E (6 $\mathrm{mL}$; PerkinElmer) as a trapping agent and PermaFluor ${ }^{\circledR} \mathrm{E}+(10 \mathrm{~mL}$; PerkinElmer) as a scintillant. Aliquots of urine and plasma were analyzed directly following the addition of $10 \mathrm{~mL}$ of Ultima Gold ${ }^{\mathrm{TM}}$ scintillation fluid. All radioactivity determinations were made using a Tri-Carb Model 3100TR liquid scintillation counter or model 2700TR (PerkinElmer) liquid scintillation counter with an Ultima Gold $^{\mathrm{TM}}$ or toluene standard curve. Counts per minute were converted to disintegrations per minute by use of external standards of known radioactivity, and the lower limits of detection were defined as twice background.

Liquid scintillation counting was used to assess mass balance of $\left[{ }^{14} \mathrm{C}\right]$-desvenlafaxine in preclinical species. An Ultima Gold ${ }^{\mathrm{TM}}$ scintillation cocktail $(10 \mathrm{~mL})$ was added to duplicate aliquots of urine samples $(0.5 \mathrm{~mL}$ each) prior to counting. Fecal samples were weighed and homogenized in deionized water at ambient temperature. Duplicate aliquots of fecal homogenate $(0.5 \mathrm{~g})$ were subjected to combustion after which the sample was oxidized in a model 307 Tri-Carb oxidizer using Carbosorb $^{\circledR} \mathrm{E}(6 \mathrm{~mL})$ as a trapping agent and PermaFluor ${ }^{\circledR} \mathrm{E}^{+}(10 \mathrm{~mL})$ as a scintillant. Oxidation efficiency was determined by oxidation of ${ }^{14} \mathrm{C}$-Spec-Chech (PerkinElmer), a standard of known radioactivity, and was determined to be $99.8 \%$.

For metabolic profiling, urine samples were centrifuged at $4^{\circ} \mathrm{C}$ for 10 minutes. Plasma aliquots $(0.5-1 \mathrm{~mL})$ and fecal homogenates $(\sim 2 \mathrm{~g})$ were mixed with an equal volume of acetonitrile, placed on ice for 10 minutes, and centrifuged at $4^{\circ} \mathrm{C}$ for 10 minutes $(16000 \times g$ in an Eppendorf Model 5415C centrifuge or $2100 \times g$ in a Sorvall Super 21 centrifuge). Supernatants were concentrated under a stream of nitrogen in a TurboVap (Caliper Life Sciences, Hopkinton, MA) to remove the acetonitrile. Samples were assayed for radiopurity using HPLC and LC/MS.

\section{Metabolite profiling and identification}

Chromatographic analysis for metabolite profiling was performed with a Waters Alliance model 2690 HPLC system (Waters Corporation, Milford, MA) equipped with a built-in autosampler and model 996 diode array detector, set to monitor 220 to $240 \mathrm{~nm}$, or inline with a model 2487 tunable UV detector, set to monitor $225 \mathrm{~nm}$, and a FloOne $\beta$ Model 515 radioactivity flow detector (PerkinElmer) with a $250-\mu \mathrm{L}$ flow cell. Separation of the metabolite peaks was accomplished on a Luna C18(2) column $(250 \times 4.6 \mathrm{~mm}, 5 \mu \mathrm{m}$, or $150 \times 2.0 \mathrm{~mm}, 5 \mu \mathrm{m}$; Phenomenex; Torrance, CA), using a linear gradient of 2 mobile phases, A (10-mM ammonium acetate, $\mathrm{pH}$ 5.5-6.0) and B (acetonitrile). Data collection and analyses were performed using Flo-One software (ver. 3.65, PerkinElmer).

For metabolite identification, a model 1100 HPLC system (Agilent Technologies, Palo Alto, CA), including an autosampler and diode 
array UV detector, was interfaced to the mass spectrometer described below. The UV detector was set to monitor 200 to $400 \mathrm{~nm}$. A linear gradient of 2 mobile phases (10-mM ammonium acetate, $\mathrm{pH} 5.5$ and acetonitrile) was used for separation with 5-micron Phenomenex Luna C18(2) column, $150 \times 2$-mm columns for LC/MS analysis. The mass spectrometer used for metabolite characterization was a Micromass Q-TOF-2 quadrupole time-of-flight mass spectrometer (Waters Corporation, Milford, MA), which was equipped with an electrospray ionization interface and operated in the positive ionization mode. LC/ MS data were analyzed using MassLynx software (ver. 3.5).

\section{Identification of CYP isozymes involved in desvenlafaxine metabolism}

To determine specific CYP enzymes involved in desvenlafaxine metabolism, chemical inhibition studies were conducted in human liver microsomes. Concentrations of chemical inhibitors were those shown previously to be effective in inhibition of specific CYP enzymes. All inhibitors except for diethyldithiocarbamate were dissolved in methanol, evaporated to dryness, and redissolved by the addition of a cold sodium/potassium phosphate buffer containing microsomes. Immediately following the addition and mixing of microsomes to dissolve the inhibitor, reactions were initiated by the addition of NADPH. Diethyldithiocarbamate was dissolved in water and added to the reaction mixture along with the other reagents. The flavin-containing monooxygenases were inactivated by heating the microsomes prior to adding them to incubations. Reactions were carried out in a water bath at $37^{\circ} \mathrm{C}$ for 30 minutes. Control incubations, consisting of all components of each mixture except NADPH, were analyzed for each sample. Following the incubations, the protein was precipitated by the addition of acetonitrile with $1-\mu \mathrm{M}$ dextrorphan added as an internal standard. Samples were shaken for 10 minutes, centrifuged, and supernatants were analyzed by LC/MS.

Specific metabolites of CYP isozyme-specific probe substrates were detected in supernatants of human liver microsomes by an LC/MS/MS assay. Chromatographic separations were conducted with an Aquasil C18 column $(2.1 \mathrm{~mm} \times 50 \mathrm{~mm}, 5 \mu \mathrm{m})$ (Thermo Scientific, Bellefonte, PA) and a mobile phase consisting of a linear gradient of $0.1 \%$ formic acid in water and acetonitrile. A Micromass Quattro Micro triple quadrupole mass spectrometer (Waters Corporation, Milford, MA) was operated in the multiple reaction monitoring technique with cone voltage and collision-activated dissociation settings optimized for each metabolite monitored.

\section{Effects of desvenlafaxine on CYP enzymatic activity}

Determination of the maximal inhibitory concentration that inhibits $50 \%\left(\mathrm{IC}_{50}\right)$ of CYP enzymatic activity by desvenlafaxine and comparator antidepressants in human liver microsomes, as well as in vitro analysis of enzymatic activity, was conducted using a "cocktail" method as described elsewhere [16,20]. Assessment of mechanismbased inhibition of CYP enzymes used probe substrates (shown in parentheses) to investigate the effects of desvenlafaxine on the enzymatic activity of CYP1A2 (ethoxyresorufin), CYP2C8 (taxol), CYP2C9 (diclofenac), CYP2C19 (S-mephenytoin), CYP2D6 (bufuralol, dextromethorphan), and CYP3A4 (midazolam).

The inhibition constant $\left(\mathrm{K}_{\mathrm{i}}\right)$ values for the inhibition of CYP2D6mediated bufuralol and dextromethorphan activities were determined in human liver microsomes that were pooled from 12 subjects. Bufuralol was added at final concentrations of 3.6, 9, 18,36, and $54 \mu \mathrm{M}$ in methanol followed by the addition of desvenlafaxine at final concentrations of 0 , $25,50,100$, and $200 \mu \mathrm{M}$, which were $0,0.5,1,2$, and 4 times the $\mathrm{IC}_{50}$ value $(50 \mu \mathrm{M})$ determined previously for the inhibition of CYP2D6 activity. Human liver microsomes were added at a final concentration of $0.5-\mathrm{mg}$ protein $/ \mathrm{mL}$, and the reactions were initiated by the addition of an NADPH-regenerating system as previously described. Inhibition of CYP2D6-mediated dextromethorphan $\mathrm{O}$-demethylase activity by desvenlafaxine was assessed using similar methodology.

\section{Transfection and induction of the CYP3A4 promoter and pregnane $\mathrm{X}$ receptor into $\mathrm{HepG} 2$ cells}

HepG2 cells were cultured in Dulbecco's modified Eagles medium supplemented with $10 \%$ fetal bovine serum, antibiotics, and antimycotics in a T75 flask $\left(5 \times 10^{6}\right.$ cells $)$. At $75 \%$ confluence, the cells were harvested and $\sim 3 \times 10^{5}$ cells/well were seeded in 12-well plates (3 wells/treatment). After 16 hours of recovery, cells were transfected with the CYP3A4 promoter and pregnane $\mathrm{X}$ receptor (PXR) plasmid DNA (250 ng each), using Fugene 6 (Roche Molecular Biochemicals, Indianapolis, IN), in a reagent to DNA ratio of 3:1

After 16 hours, transfected cells were treated with desvenlafaxine at concentrations of 2,4 , and $10 \mu \mathrm{M}$. For vehicle controls, dimethyl sulfoxide $(0.1 \%)$ was added to the culture media and for positive and negative controls, rifampicin $(10 \mu \mathrm{M})$ and penicillin $(50 \mu \mathrm{M})$ were added to the respective wells. Cells were incubated for 48 hours and treated with fresh compound at 24 hours. Cells were then lysed and luciferase activity was determined in lysates using a commercially available assay system (Promega Catalog \# E1483 [Promega Corporation, Madison, WI]). Luciferase activity, expressed as Relative Light Units, was measured using the Luminoskan Ascent Luminometer (Thermolabsystems, Helsinki, Finland). Each sample was prepared in triplicate and each replicate read in triplicate to achieve both biological and experimental replicates.

\section{Calculations}

For CYP inhibition studies, the Michaelis constant $\left(\mathrm{K}_{\mathrm{m}}\right.$, concentration of drug at which rate is $1 / 2$ maximum) for desvenlafaxine metabolism to NODV was determined using a Lineweaver-Burk plot of the rate of NODV formation at various desvenlafaxine concentrations. Values for desvenlafaxine metabolism by the various cDNAs were expressed relative to the metabolism observed in human liver microsomes using the formula: $\left(a_{c}-b_{c}\right) /\left(a_{m}-b_{m}\right)$, where $a_{c}$ is the peak area of metabolite in cDNA incubations with NADPH; $b_{c}$ is the peak area of metabolite in cDNA incubations with no NADPH; and $\mathrm{a}_{\mathrm{m}}$ and $b_{m}$ are the corresponding values for incubations of desvenlafaxine using human liver microsomes. The percent inhibition with chemical inhibitors was based on the amount of metabolite detected, and values were expressed as percent inhibition relative to a control reaction using the formula: $\%$ inhibition $=([a-b] / a)^{\star} 100 \%$, where $a=$ peak area of metabolite with no inhibitor present, and $b=$ peak area of metabolite with inhibitor present. Means and standard deviations for CYP enzymatic activity were graphed to determine the $\mathrm{IC}_{50}$ values for each CYP enzyme. If greater than $50 \%$ of the enzymatic activity was present at all desvenlafaxine concentrations for a particular substrate, the $\mathrm{IC}_{50}$ was reported as $>100 \mu \mathrm{M}$. When less than $50 \%$ of the enzymatic activity remained, the $\mathrm{IC}_{50}$ values were determined to be the concentration on the graph at which enzymatic activity was $50 \%$ of the control activity.

1'-Hydroxybufuralol and dextrorphan analyte concentrations (nM) were obtained by constructing calibration curves of peak area ratio vs concentration. Concentrations were calculated using a calibration curve for the analyte ranging from 0.5 to $50 \mathrm{nM}$, and $1 / \mathrm{x}^{2}$ weighted linear least squares regression. 
Lineweaver-Burk plots were used to determine apparent $\mathrm{K}_{\mathrm{m}}$ values for bufuralol 1'-hydroxylation and dextromethorphan $O$-demethylation in the absence of desvenlafaxine. Dixon plots were used to determine $\mathrm{K}_{\mathrm{i}}$ values, which were calculated by averaging the points of intersection for all of the lines. The type of inhibition (ie, competitive or noncompetitive) was determined by analyzing both the Lineweaver-Burk and Dixon plots.

The pharmacokinetic parameters for $\left[{ }^{14} \mathrm{C}\right]$-desvenlafaxine-derived radioactivity were calculated using the noncompartmental analysis module of WinNonlin, version 4.1, (Scientific Consultants, Inc., Research Triangle Park, NC). The peak plasma concentration $\left(\mathrm{C}_{\mathrm{max}}\right)$ and the corresponding time to $\mathrm{C}_{\max }$ were obtained directly from the individual concentration-time data. The apparent terminal-phase elimination half-life $\left(t_{1 / 2}\right)$ was calculated as the $\ln 2 / \lambda_{z}$ where $\lambda_{z}$ is derived from the terminal slope of the concentration time curve using at least 3 quantifiable measurements. The area under the plasma concentrationvs-time curve $(\mathrm{AUC})$ from zero to infinity $\left(\mathrm{AUC}_{0-\infty}\right)$ was calculated as $\mathrm{AUC}_{0-\mathrm{t}}+\mathrm{C}_{\text {last }} / \lambda_{\mathrm{z}}$, using the linear trapezoidal rule where $\mathrm{C}_{\text {last }}$ is the last measurable plasma concentration. All plasma and tissue radioactivity concentrations were expressed as the amounts of radioactivity equivalent to that of $\left[{ }^{14} \mathrm{C}\right]$-desvenlafaxine in nanograms per gramweight of plasma or tissue, and were calculated as: radioactivity concentration $=\mathrm{nCi}$ of ${ }^{14} \mathrm{C} / \mathrm{g}$ of plasma or tissue/nCi of ${ }^{14} \mathrm{C} / \mathrm{ng}$ of $\left[{ }^{14} \mathrm{C}\right]-$ desvenlafaxine, where $\mathrm{nCi}$ of ${ }^{14} \mathrm{C} / \mathrm{g}$ of plasma or tissue is determined by quantitative whole body autoradiography (QWBAR) or quantitative tissue dissection (QTD) and $\mathrm{nCi}$ of ${ }^{14} \mathrm{C} / \mathrm{ng}$ of $\left[{ }^{14} \mathrm{C}\right]$-desvenlafaxine is the specific activity of the test article in the dosing formulation.

\section{Results}

\section{Excretion of $\left[{ }^{14} \mathrm{C}\right]$-desvenlafaxine drug-related material in animals}

In preclinical species (ie, dogs, rats, mice), urine was the predominant route of excretion of $\left[{ }^{14} \mathrm{C}\right]$-desvenlafaxine. Urinary excretion of $\left[{ }^{14} \mathrm{C}\right]$-desvenlafaxine was rapid, with the majority of the dose recovered within 24 to 48 hours of administration. For example, in male beagle dogs, $83.7 \% \pm 8.6 \%$ of $\left[{ }^{14} \mathrm{C}\right]$-desvenlafaxine was recovered within 48 hours, and urinary and fecal excretion of radioactivity on day 7 was $<0.1 \%$ of the dose. In Sprague Dawley rats, $91.0 \% \pm 4.2 \%$ of the radioactive dose was excreted within 24 hours, and urinary and fecal excretion of radioactivity on day 5 was $<0.2 \%$ of the total dose. In male CD-1 mice, complete recovery of $\left[{ }^{14} \mathrm{C}\right]$-desvenlafaxine occurred by 24 hours postdose. Less than $2 \%$ of the radioactive dose was excreted in feces.

\section{Total radioactivity of desvenlafaxine in animals}

Mean plasma radioactivity concentrations of $\left[{ }^{14} \mathrm{C}\right]$-desvenlafaxine in dogs were $13.3,16.9,7.4$, and $0.81 \mu$ g equivalents $/ \mathrm{mL}$ at $1,4,8$, and 24 hours postdose, respectively; mean plasma concentrations of total radioactivity in mice were $13.2,2.47$, and $0.22 \mu \mathrm{g}$ equivalents $/ \mathrm{mL}$ at 1 , 4 , and 8 hours postdose, respectively; and mean plasma concentrations of total radioactivity in male rats were $11.0,1.48,0.89$, and $0.07 \mu \mathrm{g}$ equivalents/mL at $1,4,8$, and 24 hours postdose, respectively. For female rats, mean plasma concentrations of total radioactivity were 9.9 and $0.92 \mu \mathrm{g}$ equivalents $/ \mathrm{mL}$ at 1 and 8 hours postdose, respectively. No significant differences were observed in the concentration of radioactivity detected in blood or plasma of male and female rats.

Assessments of the tissue distribution of $\left[{ }^{14} \mathrm{C}\right]$-desvenlafaxinederived radioactivity in Sprague Dawley rats showed that the radioactivity $\mathrm{C}_{\text {max }}$ in tissues ranged from $107 \mu$ g equivalent/g (urinary bladder wall) to $0.719 \mu \mathrm{g}$ equivalent/g (cerebrum). Peak tissue radioactivity concentrations were observed at 0.5 hours in all tissues examined except the large intestine ( 8 hours). The tissue radioactivity $\mathrm{t}_{1 / 2}$ in the liver, kidney (cortex), small intestine, and bone were 44, $37.6,28.5$, and 13.1 hours, respectively. The radioactivity $t_{1 / 2}$ in the remaining tissues was generally less, and ranged from 1.4 hours in the thyroid gland to 5.6 hours in the large intestine. The highest tissue $\left[{ }^{14} \mathrm{C}\right]$-desvenlafaxine-derived radioactivity exposures $\left(\mathrm{AUC}_{0-\infty}\right)$ were $398,328,254,140,107,103,100$, and $84.6 \mu \mathrm{g}$ equivalent ${ }^{\star} \mathrm{h} / \mathrm{g}$ in the urinary bladder, liver, kidney medulla AUC from 0 to 120 hours $\left(\mathrm{AUC}_{0-120}\right)$, small intestine, whole kidney $\left(\mathrm{AUC}_{0-120}\right)$, large intestine, stomach, and kidney cortex, respectively. The tissue/plasma distribution of $\left[{ }^{14} \mathrm{C}\right]$-desvenlafaxine-derived radioactivity exposure ratio was $<1$ for most tissues, indicating limited distribution of $\left[{ }^{14} \mathrm{C}\right]$-desvenlafaxine and its metabolites to tissues after a single, oral dose.

\section{In vitro metabolism of desvenlafaxine}

In vitro assessment of desvenlafaxine metabolism in human and animal liver microsomes and human hepatocytes by LC/ MS/MS identified 10 metabolites and one degradation product of desvenlafaxine (Figure 1). Glucuronidation, oxidation, and $\mathrm{N}$-demethylation were the major metabolic pathways of desvenlafaxine identified, and in each metabolic system, the $O$-glucuronide metabolite of the parent compound was the only glucuronidation product detected (Figure 2). Liver microsomes from rats and dogs produced more hydroxyl metabolites compared with human liver microsomes or human hepatocytes. Only $\mathrm{O}$-glucuronidation and $\mathrm{N}$-demethylation of desvenlafaxine occurred in liver microsomes from CD-1 mice.

Because of low reaction yields in the analysis of the major UGT isoforms involved in the metabolism of $\left[{ }^{14} \mathrm{C}\right]$-desvenlafaxine, radiographic peaks of desvenlafaxine- $O$-glucuronide were not observed in human liver microsomes or UGT isozyme preparations. LC/MS/MS analysis in the selected reaction monitoring mode identified UGT1A1, $1 \mathrm{~A} 3,2 \mathrm{~B} 4,2 \mathrm{~B} 15$, and $2 \mathrm{~B} 17$ as isoforms contributing to desvenlafaxine$\mathrm{O}$-glucuronide formation.

Assessment of the CYP isozymes involved in the metabolism of desvenlafaxine identified 2 major metabolites, including NODV $\left(\mathrm{K}_{\mathrm{m}}\right.$ $=290 \mu \mathrm{M})$, which was produced via $N$-demethylation, and benyzl hydroxy desvenlafaxine (estimated $\mathrm{K}_{\mathrm{m}}=350 \mu \mathrm{M}$ ), which was produced by hydroxylation on the benzyl group. Several of the cDNA isoforms evaluated were capable of metabolizing desvenlafaxine to various extents, including CYP2C19, CYP3A4, CYP2C8, and CYP2C9. No metabolism of desvenlafaxine was detected with CYP1A2, CYP1A2, CYP2A6, or CYP2D6. Based on relative amounts of CYP enzymes found in liver microsomes and the chemical inhibition study results, the primary CYP isozyme involved in desvenlafaxine metabolism was determined to be CYP3A4 (Table 1). Inhibitors of CYP2C9 and CYP2E1 exhibited mild effects on desvenlafaxine metabolism.

\section{Metabolic profiles in animals}

Desvenlafaxine-O-glucuronide was the predominant radioactive component in plasma of preclinical species: $78 \%$ and $96 \%$ of the circulating radioactivity at 1 and 4 hours postdose, respectively, in dogs; $88 \%$ and $95 \%$, respectively, in mice; and $89 \%$ and $94 \%$, respectively, in male rats (Figure 3). No significant differences in desvenlafaxine metabolism were observed in male vs female rats.

Desvenlafaxine- $O$-glucuronide was the predominant radioactive peak in urine samples from preclinical species $(75 \%-85 \%$ of radioactivity). In dogs and mice, unchanged desvenlafaxine was the 
Citation: DeMaio W, Kane CP, Nichols AI, Jordan R (2011) Metabolism Studies of Desvenlafaxine. J Bioequiv Availab 3: 151-160. doi:10.4172/ jbb.1000076

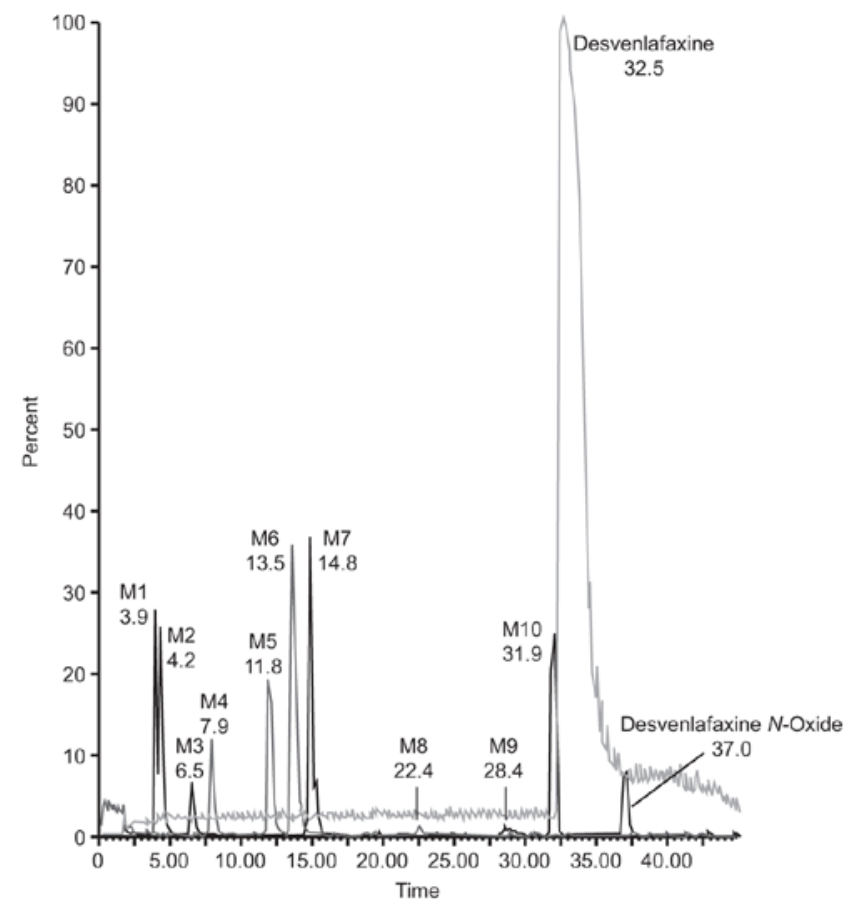

Figure 1: Representative liquid chromatography/mass spectrometry overlaid mass chromatograms of desvenlafaxine and desvenlafaxine metabolites generated in vitro from incubation of rat liver microsomes with $300-\mu \mathrm{M}$ desvenlafaxine in the presence of an nicotinamide adenine dinucleotide phosphate generating system and uridine 5'-diphosphoglucuronic acid triammonium salt.

predominant peak of fecal extracts $(76 \%$ and $34 \%$ of radioactivity, respectively). However, in Sprague Dawley rats, NODV was the predominant component of fecal extracts (34\% radioactivity).

\section{Metabolic profiles in humans}

Desvenlafaxine was the predominant drug-related component in human plasma following a single $300-$ or $600-\mathrm{mg}$ oral dose of desvenlafaxine (Figure 3). Desvenlafaxine-O-glucuronide was the second most abundant drug-related component in plasma, representing $20 \%$ to $80 \%$ relative to the amount of desvenlafaxine, based on LC/MS chromatographic peak areas (Table 2). Desvenlafaxine concentrations were similar in 6- and 12-hour pooled samples, and desvenlafaxine- $O$ glucuronide concentrations were consistently highest in the 12-hour samples. Additional minor metabolites detected in human plasma were NODV and NODV-O-glucuronide. No other desvenlafaxine metabolites were detected in human plasma samples.

\section{Effects of desvenlafaxine on CYP enzymes}

Although CYP3A4 is a mediator of desvenlafaxine metabolism, desvenlafaxine did not induce human CYP3A4 in transfected HepG2 cells at concentrations as high as $10 \mu \mathrm{M}$, which is more than 15 times the $\mathrm{C}_{\max }$ of desvenlafaxine observed by Nichols et al. [16] following 50-mg IV or 100-mg oral administration of desvenlafaxine in healthy adults $\left(\mathrm{C}_{\max }=0.88 \mu \mathrm{M}\right.$ and $0.61 \mu \mathrm{M}$, respectively). No significant inhibition of CYP1A2, CYP2C8, CYP2C9, CYP2C19, or CYP3A4 enzymatic activity $\left(\mathrm{IC}_{50}>100 \mu \mathrm{M}\right)$ was observed at any desvenlafaxine concentration tested (Table 3). In addition, in 2 separate tests, desvenlafaxine concentrations $\geq 10 \mu \mathrm{M}$ inhibited CYP2D6-mediated metabolism of bufuralol $\left(\mathrm{IC}_{50}=\right.$ $50 \mu \mathrm{M}$ and $70 \mu \mathrm{M})$ and dextromethorphan $\left(\mathrm{IC}_{50}=80 \mu \mathrm{M}\right.$ and $\left.90 \mu \mathrm{M}\right)$.
In addition, no evidence for mechanism-based irreversible inhibition by desvenlafaxine of CYP2C9, CYP2C19, CYP2D6, or CYP3A4 was observed.

The $\mathrm{K}_{\mathrm{i}}$ for bufuralol 1'-hydroxylase was approximately $80 \mu \mathrm{M}$ and the $\mathrm{K}_{\mathrm{i}}$ for dextromethorphan $O$-demethylase was approximately $40 \mu \mathrm{M}$. These $\mathrm{K}_{\mathrm{i}}$ values were only estimates because of the apparently mixed inhibition consisting of reversible competitive and noncompetitive inhibition; however, these values confirm the low to moderate inhibitory effect of desvenlafaxine on CYP2D6 in vitro. These findings also suggest that only minor inhibition of CYP2D6 is likely following the oral administration of desvenlafaxine, because the plasma $\mathrm{C}_{\text {max }}$ of desvenlafaxine following a 100 -mg oral dose $(0.4 \mu \mathrm{M})$ is $\sim 0.5 \%$ to $1.0 \%$ of the $\mathrm{K}_{\mathrm{i}}$ values [16].

Similar results were observed in human liver microsomes. Desvenlafaxine showed no inhibition of CYP2A6, CYP2C8, CYP2C9, CYP2C19, CYP2D6, or CYP3A at the highest concentration evaluated $(100 \mu \mathrm{M})$, and only weakly inhibited CYP1A2 activity $\left(\mathrm{IC}_{50}=130\right.$ $\mu \mathrm{M}$ ). In contrast, many of the comparator antidepressants studied (at concentrations of $100 \mu \mathrm{M}$ ) inhibited many of the CYP enzymes tested, including CYP2D6 $\left(\mathrm{IC}_{50}\right.$ and \% of $\mathrm{C}_{\max }$ based on reported values for therapeutic doses ${ }^{21-24}$ duloxetine: $6.0 \mu \mathrm{M}, 2.4-5.5 \%$; paroxetine: $2.0 \mu \mathrm{M}$,

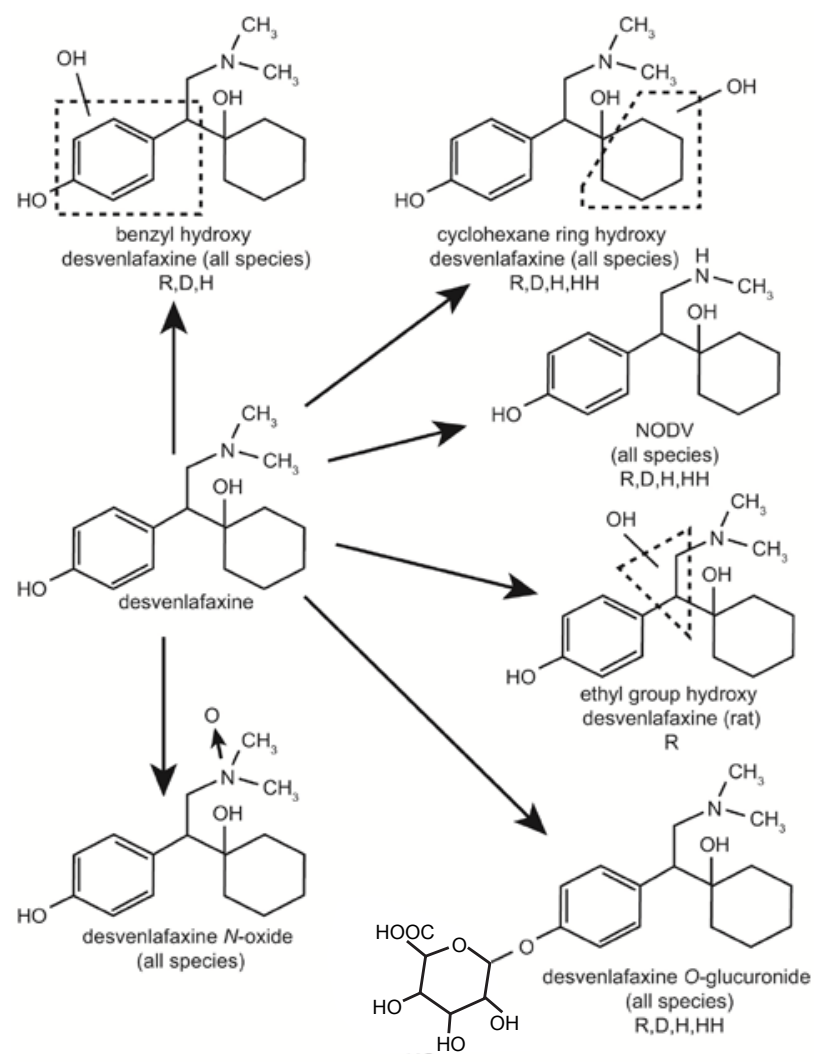

Figure 2: The primary desvenlafaxine metabolites and reaction products detected in vitro using cryopreserved human hepatocytes and liver microsomes from rat, dog, and human. Rat liver microsomes produced 8 hydroxyl desvenlafaxine metabolites ( 6 cyclohexane ring hydroxyl metabolites, 1 ethyl group hydroxyl metabolite, and 1 benzyl group hydroxyl metabolite). Dog liver microsomes produced all hydroxyl metabolites except the ethyl group hydroxyl metabolite. Human liver microsomes produced 3 cyclohexane ring hydroxyl metabolites and the benzyl group hydroxyl metabolite. All species generated $\mathrm{N}, \mathrm{O}$-didesmethylvenlafaxine (NODV), desvenlafaxine O-glucuronide, and the reaction product desvenlafaxine $\mathrm{N}$-oxide. 
Citation: DeMaio W, Kane CP, Nichols AI, Jordan R (2011) Metabolism Studies of Desvenlafaxine. J Bioequiv Availab 3: 151-160. doi:10.4172/ jbb.1000076
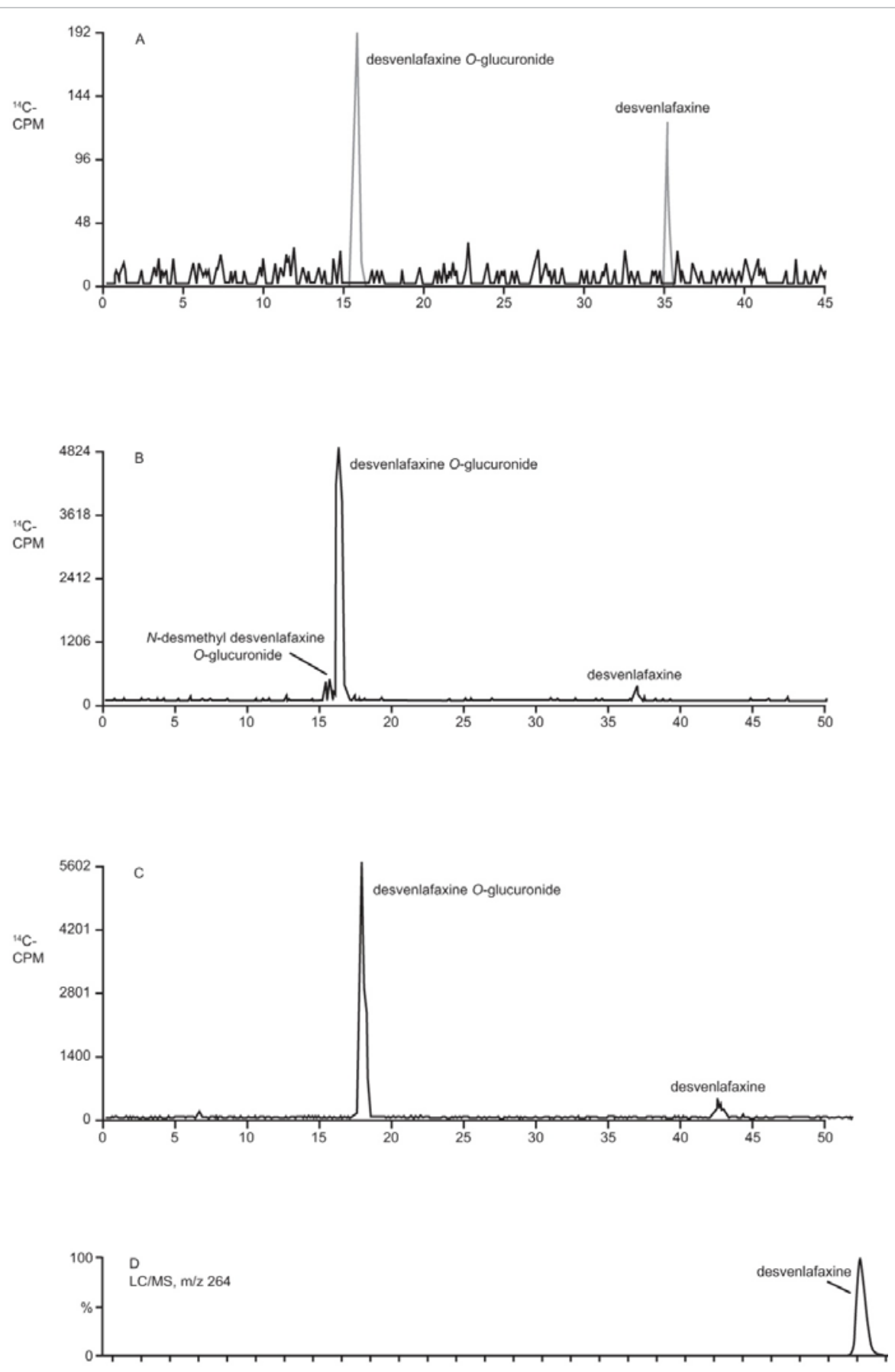

Figure 3: Representative plasma metabolite profiles in vivo 1 hour following administration of a single, oral dose of desvenlafaxine in (A) dogs (30 mg/kg), (B) male mice (30 mg/kg), (C) male rats $(20 \mathrm{mg} / \mathrm{kg})$, and (D) 6 hours following administration of $600-\mathrm{mg}$ desvenlafaxine in humans.

8.2\%; sertraline $5.0 \mu \mathrm{M}, 8.3 \%$; bupropion: $28 \mu \mathrm{M}, 2 \%$ ), and CYP2C19 $\left(\mathrm{IC}_{50}\right.$ and \% of $\mathrm{C}_{\max }$ : duloxetine: $49 \mu \mathrm{M}, 0.3-0.7 \%$; paroxetine: $70 \mu \mathrm{M}$, $0.2 \%$; sertraline: $27 \mu \mathrm{M}, 1.5 \%$; bupropion: $43 \mu \mathrm{M}, 1.3 \%)$.

\section{Discussion}

These findings from multiple assessments indicate that the primary metabolic pathways for desvenlafaxine include glucuronidation, oxidation, and $\mathrm{N}$-demethylation. Although CYP3A4 was the primary CYP isozyme involved in oxidative metabolism, this pathway is only minimally involved. The limited involvement of CYP enzymes in desvenlafaxine metabolism decreases the likelihood of alterations in desvenlafaxine pharmacokinetics because of CYP polymorphisms or CYP-mediated DDIs. Indeed, Preskorn and colleagues [25] demonstrated no appreciable impact of the CYP2D6 metabolizer phenotype (ie, extensive CYP2D6 metabolizers vs poor CYP2D6 metabolizers) on the pharmacokinetic parameters of a single dose of desvenlafaxine $100 \mathrm{mg}$. In addition, a separate study demonstrated that concomitant administration of the CYP3A4 inhibitor ketoconzaole 
Citation: DeMaio W, Kane CP, Nichols AI, Jordan R (2011) Metabolism Studies of Desvenlafaxine. J Bioequiv Availab 3: 151-160. doi:10.4172/ jbb.1000076

only modestly impacted the pharmacokinetic parameters and urinary excretion patterns of desvenlafaxine (Figure 4) [26].

Desvenlafaxine-O-glucuronide was the predominant molecular species in plasma and urine, and urine was the primary route of excretion of desvenlafaxine in mice, rats, and dogs. The tissue/plamsa distribution of $\left[{ }^{14} \mathrm{C}\right]$-desvenlafaxine-derived radioactivity in rats, mice and dogs was $<1$ for most tissues. Given that desvenlafaxine-Oglucuronide was the predominate species in plasma, this metabolite plays a major role in the limited distribution to tissues as calculated by the tissue/plasma ratio. In contrast to preclinical species, desvenlafaxine$O$-glucuronide accounted for only $20 \%$ to $80 \%$ relative to the amount of desvenlafaxine, which was the predominant molecular species in human plasma. The lower amounts of desvenlafaxine-O-glucuronide in human plasma would suggest that the tissue/plasma ratio in humans would likely be higher than that observed in preclinical species. This is also supported by the fact that the volume of distribution at steadystate for desvenlafaxine in humans is $3.42 \mathrm{~L} / \mathrm{kg}$.

The mean absolute bioavailability of orally administered desvenlafaxine in humans was $80.5 \%$; the concentrations of $(R)$ - and $(S)$-desvenlafaxine enantiomers in all plasma samples assayed were approximately equal, and demonstrated similar pharmacokinetic parameters [16]. For preclinical species, absolute bioavailability of orally administered desvenlafaxine was only determined in dogs and ranged between 31 to $42 \%$. This is consistent with the fact that unchanged desvenlafaxine was the predominant peak (76\%) in fecal extracts for dogs. Fecal elimination was not determined in humans, however, urinary excretion of conjugated and unconjugated desvenlafaxine and NODV accounted for the majority of the administered desvenlafaxine dose following both oral (69\%) and IV (76\%) administration [16]. In contrast to preclinical species where desvenlafaxine-O-glucuronide was the predominant molecular species in urine, excretion of desvenlafaxine in human urine accounted for $45 \%$ of administered drug while desvenlafaxine-O-glucuronide accounted for only $19 \%$ of drug eliminated in urine [16]. Involvement of multiple human UGT enzymes in desvenlafaxine metabolism suggests that a deficiency in one isozyme is not likely to significantly alter desvenlafaxine metabolism. Despite its renal elimination, the magnitude of variation in desvenlafaxine pharmacokinetics occurring with reduced renal function is such that dosage reduction is recommended only in those patients with severe renal impairment or end-stage renal disease [27]. Less than $5 \%$ of the administered dose appeared in the urine as the

\begin{tabular}{|l|l|l|l|l|}
\hline Inhibitor & $\mathbf{M}$ & E.nzyme Inhibited & Percent Inhibition of NODV Formation & Percent Inhibition of Benzyl Hydroxyl Desvenlafaxine Formation $^{\mathbf{a}}$ \\
\hline a-Naphthoflavone & 1 & CYP1A2 & 0 & 0 \\
\hline Coumarin & 100 & CYP2A6 & 0 & 0 \\
\hline Sulfaphenazole & 10 & CYP2C9 & 21 & 0 \\
\hline S(+)-Mephenytoin & 100 & CYP2C19 & 0 & 0 \\
\hline Quinidine & 10 & CYP2D6 & 4 & 0 \\
\hline Diethyldithiocarbamate & 100 & CYP2E1 & 15 & 19 \\
\hline \multirow{2}{*}{ Ketoconazole } & 50 & CYP3A4 & 76 & 58 \\
\hline Benzylimidazole & 1000 & CYP3A4 & 65 & 29 \\
\hline Heat inactivation & 1 min at $50^{\circ} \mathrm{C}$ & FMO & 29 & 0 \\
\hline
\end{tabular}

aValues are expressed as percent inhibition relative to a control reaction using the formula: $\%$ inhibition $=([a-b] / a * 100 \%)$, where a $=$ peak area of metabolite with no inhibitor present, and $b=$ peak area of metabolite with inhibitor present.

Abbreviations: CYP, cytochrome P450; FMO, flavin-containing monooxygenase.

Table 1: Inhibition of Desvenlafaxine Metabolism by Specific Isozyme Inhibitors in Human Liver Microsomes.

\begin{tabular}{|c|c|c|c|c|c|c|}
\hline \multirow{2}{*}{$\begin{array}{l}\text { Treatment Group (Subject } \\
\text { Number) }\end{array}$} & \multirow{2}{*}{ Dose (mg) } & \multirow{2}{*}{ Time Point (h) } & \multicolumn{3}{|c|}{ Metabolite to Desvenlafaxine LC/MS Peak Area Ratio } & \multirow{2}{*}{$\begin{array}{l}\text { Estimated Desvenlafaxine Concentration } \\
(\mathrm{ng} / \mathrm{mL})\end{array}$} \\
\hline & & & M13 & M7 & NODV & \\
\hline \multirow{9}{*}{$\begin{array}{l}\text { A } \\
(1,17)\end{array}$} & \multirow{3}{*}{300} & \multirow{3}{*}{$\begin{array}{l}6 \\
12 \\
24\end{array}$} & ND & 0.29 & ND & 699 \\
\hline & & & 0.007 & 0.65 & ND & 687 \\
\hline & & & 0.011 & 0.44 & ND & 314 \\
\hline & \multirow{3}{*}{600} & \multirow{3}{*}{\begin{tabular}{|l}
6 \\
12 \\
24
\end{tabular}} & ND & 0.36 & ND & 1393 \\
\hline & & & 0.006 & 0.80 & 0.002 & 1194 \\
\hline & & & 0.014 & 0.71 & 0.007 & 638 \\
\hline & \multirow{3}{*}{300} & \multirow{3}{*}{$\begin{array}{l}6 \\
12 \\
24\end{array}$} & ND & 0.27 & ND & 625 \\
\hline & & & 0.006 & 0.45 & ND & 499 \\
\hline & & & ND & 0.35 & ND & 287 \\
\hline \multirow{6}{*}{$\begin{array}{l}\text { B } \\
(6,11,16,19)^{\mathrm{a}}\end{array}$} & \multirow{3}{*}{600} & \multirow{3}{*}{$\begin{array}{l}6 \\
12 \\
24\end{array}$} & ND & 0.33 & ND & 1301 \\
\hline & & & 0.005 & 0.48 & 0.003 & 1269 \\
\hline & & & 0.004 & 0.35 & 0.005 & 827 \\
\hline & \multirow{3}{*}{300} & \multirow{3}{*}{\begin{tabular}{|l}
6 \\
12 \\
24
\end{tabular}} & ND & 0.21 & ND & 663 \\
\hline & & & ND & 0.34 & ND & 621 \\
\hline & & & ND & 0.23 & ND & 362 \\
\hline \multirow{3}{*}{$\begin{array}{l}\mathrm{E} \\
(4,12,13,23)\end{array}$} & \multirow{3}{*}{600} & \multirow{3}{*}{$\begin{array}{l}6 \\
12 \\
24\end{array}$} & ND & 0.31 & 0.002 & 1345 \\
\hline & & & 0.004 & 0.48 & 0.003 & 1230 \\
\hline & & & 0.005 & 0.28 & 0.005 & 787 \\
\hline
\end{tabular}

Table 2: Desvenlafaxine Metabolite LC/MS Response Relative to Desvenlafaxine in Pooled Plasma Samples From Healthy Volunteers After a Single Oral Dose of Desvenlafaxine $300 \mathrm{mg}$ or $600 \mathrm{mg}$. 
Citation: DeMaio W, Kane CP, Nichols AI, Jordan R (2011) Metabolism Studies of Desvenlafaxine. J Bioequiv Availab 3: 151-160. doi:10.4172/ jbb.1000076

\begin{tabular}{|c|c|c|}
\hline CYP Isozyme & $\begin{array}{l}\text { IC }_{50} \text { for } \\
\text { Desvenlafaxine }\end{array}$ & $\begin{array}{l}\text { IC } \text { for CYP-Specific }_{50} \\
\text { Inhibitor }\end{array}$ \\
\hline CYP1A2 & $>100 \mu \mathrm{M}$ & $\begin{array}{l}0.02 \mu \mathrm{M} \\
\alpha-N a p h t h o f l a v o n e\end{array}$ \\
\hline CYP2C8 & $>100 \mu \mathrm{M}$ & $\begin{array}{l}10 \mu \mathrm{M} \\
\text { Quercitin }\end{array}$ \\
\hline CYP2C9 & $>100 \mu \mathrm{M}$ & $\begin{array}{l}1 \mu \mathrm{M} \\
\text { Sulfaphenazole }\end{array}$ \\
\hline CYP2C19 & $>100 \mu \mathrm{M}$ & $\begin{array}{l}20 \mu \mathrm{M} \\
\text { Tranylcypromine }\end{array}$ \\
\hline CYP2D6: Bufuralol cocktaila & $50 \mu \mathrm{M}$ & $\begin{array}{l}0.2 \mu \mathrm{M} \\
\text { Quinidine }\end{array}$ \\
\hline CYP2D6: Bufuralol & $70 \mu \mathrm{M}$ & ND \\
\hline CYP2D6: Bufuralol plus desvenlafaxine & $50 \mu \mathrm{M}$ & ND \\
\hline CYP2D6: Dextromethorphan ${ }^{b}$ & $80 \mu \mathrm{M}$ & ND \\
\hline $\begin{array}{l}\text { CYP2D6: Dextromethorphan plus } \\
\text { desvenlafaxine }^{b}\end{array}$ & $90 \mu \mathrm{M}$ & ND \\
\hline CYP3A4 & $>100 \mu \mathrm{M}$ & $\begin{array}{l}0.08 \mu \mathrm{M} \\
\text { Ketoconazole }\end{array}$ \\
\hline
\end{tabular}

aprobe utilized as component of a cocktail.

bIn a separate set of experiments, bufuralol and dextromethorphan $(5 \mu \mathrm{M})$ were analyzed separately with the internal standard 4'-hydroxydiclofenac $(0.53 \mu \mathrm{M})$. These substrates were incubated separately so they would not inhibit each other's metabolism, did not include control incubations containing a known CYP2D6 inhibitor, and the incubations were performed twice; desvenlafaxine $30 \mu \mathrm{M}$ was added to the second set of incubations.

Abbreviations: CYP, cytochrome P450; $\mathrm{IC}_{50}$, half-maximal inhibitory concentration; ND, not determined.

Table 3: Approximate $\mathrm{IC}_{50}$ Values for Desvenlafaxine and Known Inhibitors of Specific CYP Enzymes.

\section{A}

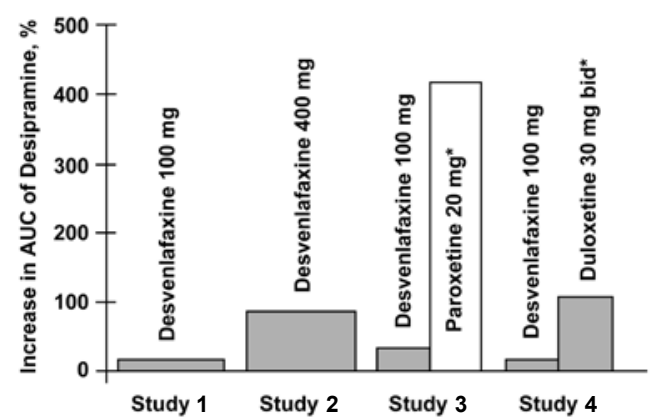

B

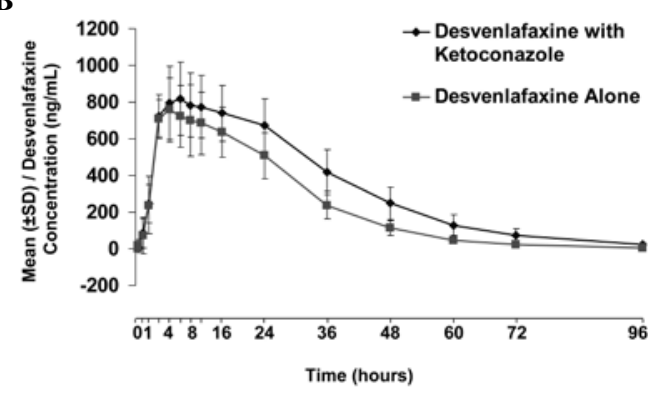

Figure 4: (A) Ratio of least squares geometric mean desipramine AUC values for studies comparing desipramine plus desvenlafaxine vs desipramine alone. From Preskorn et al. J Psychiatr Pract [29]. Plasma concentrations (ie, AUC and peak plasma concentration) of desipramine, a substrate probe for cytochrome P450 2D6 activity, and 2-hydroxydesipramine, the metabolite of desipramine hydroxylation by CYP2D6, were compared in subjects administered desipramine alone and in subjects administered desipramine in combination with desvenlafaxine using a 1-factor analysis of variance. (B) Mean (SD) AUC profiles of (R+S)-enantiomers of desvenlafaxine after a single oral dose of desvenlafaxine $400 \mathrm{mg} / \mathrm{d}$ with and without ketoconazole $200 \mathrm{mg}$ twice daily in healthy subjects. Abbreviations: AUC, area under the plasma-concentration-vs-time curve; bid, twice daily. From Nichols et al. [26].

oxidative metabolite NODV, reinforcing the limited role of first-pass metabolism [16].

In the present study, desvenlafaxine showed little or no reversible inhibition of various CYP enzymes, and did not act as an irreversible mechanism-based inhibitor of CYP2C9, CYP2C19, CYP2D6, or CYP3A4. These findings are in agreement with those of Oganesian and colleagues [28], who evaluated the inhibitory potency of desvenlafaxine on CYP enzymes and P-glycoprotein (P-gp) in vitro (human liver microsomes and Caco- 2 cell monolayers, respectively). In that study, desvenlafaxine exhibited little or no inhibition $\left(\mathrm{IC}_{50}>100 \mu \mathrm{M}\right)$ of CYP1A2, CYP2A6, CYP2C8, CYP2C9, CYP2C19, or CYP3A4 activity, and did not inhibit CYP2D6 activity. In addition, the inhibitory potency of desvenlafaxine for P-gp was low (efflux ratio for desvenlafaxine 100 $\mu \mathrm{M}=1.3$; efflux ratio $<2$ indicates no inhibition) [28]. Additional clinical studies have demonstrated the relative minimal impact of desvenlafaxine on the pharmacokinetics of the CYP2D6 substrate desipramine [29] and the CYP3A substrate midazolam [26] (Figure 4).

Characteristics such as a simple metabolic profile, the lack of a clinically significant effect on CYP enzyme activity, and no discernible interaction with P-gp transport enzymes are of particular importance to enhanced tolerance of treatment. Desvenlafaxine is unlikely to act as the perpetrator in CYP- or P-gp-mediated DDIs, and central infiltration of desvenlafaxine is unlikely to be affected by $\mathrm{P}$-gp modulators or clinical situations that affect $\mathrm{P}$-gp activity. The minimal effect of CYP enzymes on desvenlafaxine points to the potential for a more consistent systemic exposure, which may lead to a more consistent exposure of desvenlafaxine at its site of action in the central nervous system. In addition, the limited effect of desvenlafaxine on CYP enzymes and P-gp suggests a reduced risk for tolerability issues with desvenlafaxine coadministration, which may improve patient adherence to desvenlafaxine and coadministered medications. This latter point is of particular importance in patients with MDD, who are frequently taking many medications, thus making CYP-mediated DDIs more likely to occur [30].

\section{Clinical Implications}

Attributes of relatively simple metabolism and low potential for certain DDIs are important for the long-term treatment of patients with MDD who require chronic disease management. With the increasing appreciation of pharmacogenetic- and phenoconversiondriven variations in therapeutic response, agents that avoid interactions with systems that are well known to differentially affect patient outcomes have a natural advantage in this subset of patients. Until pharmacogenetic screening becomes commonplace, and until our understanding of the role and variability of P-gp activity (and other systems affecting drug disposition and patient response) develop further, such agents represent a favorable clinical option for patient care across the entire population. The metabolic properties of desvenlafaxine suggest a minimal likelihood of clinically significant CYP-mediated DDIs, and the pharmacokinetic parameters and central availability of desvenlafaxine are likely to be consistent across a patient population, regardless of CYP enzyme metabolizer phenotype. The simple metabolic profile of desvenlafaxine may thus lead to clinical benefits in the treatment of patients with MDD.

\section{Disclosure}

Alice I. Nichols, $\mathrm{PhD}$, is an employee of Pfizer Inc, formerly Wyeth Research. William DeMaio, PhD, Cecelia P. Kane, MD, and Ronald Jordan, PhD, are former Pfizer Inc employees. 
Citation: DeMaio W, Kane CP, Nichols AI, Jordan R (2011) Metabolism Studies of Desvenlafaxine. J Bioequiv Availab 3: 151-160. doi:10.4172/ jbb.1000076

\section{Acknowledgments}

We would like to acknowledge Matthew Hoffman, PhD (Matt Hoffmann and Jim Wang) and Jim Wang, PhD (Matt Hoffmann and Jim Wang) for their contributions to the studies detailed in this manuscript. This study was sponsored by Wyeth which was acquired by Pfizer Inc in October 2009. Medical writing support was provided by Callie Grimes, PhD, and Dennis Stancavish, MA, of Embryon, LLC a Division of Advanced Health Media, LLC; medical editing support was provided by Lorraine Sweeney, BA, of Embryon, LLC, and Steven J. Cally, PhD, formerly of Advogent. This assistance was funded by Wyeth, which was acquired by Pfizer Inc in October 2009

\section{References}

1. Kessler RC, Berglund P, Demler O, Jin R, Merikangas KR, et al. (2005) Lifetime prevalence and age-of-onset distributions of DSM-IV disorders in the National Comorbidity Survey Replication. Arch Gen Psychiatry 62: 593-602.

2. Andrews $\mathrm{G}$ (2001) Should depression be managed as a chronic disease? BM 322: 419-421.

3. Trivedi MH, Rush AJ, Wisniewski SR, Nierenberg AA, Warden D, et al. (2006) Evaluation of outcomes with citalopram for depression using measurementbased care in STAR*D: implications for clinical practice. Am J Psychiatry 163 : $28-40$

4. Masand PS (2003) Tolerability and adherence issues in antidepressan therapy. Clin Ther 25: 2289-2304.

5. Center for Drug Evaluation and Research, US Food and Drug Administration, Office of Generic Drugs (2008) Approved drug products with therapeutic equivalence evaluations, cumulative supplement 11. (28th ed) Center for Drug Evaluation and Research; US Food and Drug Administration; Office of Generic Drugs, Bethesda, MD.

6. Pristiq [prescribing information]. Philadelphia, PA: Wyeth Pharmaceuticals Inc.; 2009.

7. Speroff L, Gass M, Constantine G, Olivier S (2008) Efficacy and tolerability of desvenlafaxine succinate treatment for menopausal vasomotor symptoms: a randomized controlled trial. Obstet Gynecol 111: 77-87.

8. Archer DF, Seidman L, Constantine GD, Pickar JH, Olivier S (2009) A double-blind, randomly assigned, placebo-controlled study of desvenlafaxine efficacy and safety for the treatment of vasomotor symptoms associated with menopause. Am J Obstet Gynecol 200: 172.e1-172.e10.

9. Archer DF, Dupont CM, Constantine GD, Pickar JH, Olivier S (2009) Desvenlafaxine for the treatment of vasomotor symptoms associated with menopause: a double-blind, randomized, placebo-controlled trial of efficacy and safety. Am J Obstet Gynecol 200: 238.e1-238.e10.

10. Deecher DC, Beyer CE, Johnston G, Bray J, Shah S, et al. (2006) Desvenlafaxine succinate: a new serotonin and norepinephrine reuptake inhibitor. J Pharmacol Exp Ther 318: 657-665.

11. Howell SR, Husbands GE, Scatina JA, Sisenwine SF (1993) Metabolic disposition of $14 \mathrm{C}$-venlafaxine in mouse, rat, dog, rhesus monkey and man. Xenobiotica 23: 349-359.

12. Boyer P, Montgomery S, Lepola U, Germain JM, Brisard C, et al. (2008) Efficacy, safety, and tolerability of fixed-dose desvenlafaxine 50 and 100 $\mathrm{mg} /$ day for major depressive disorder in a placebo-controlled trial. Int Clin Psychopharmacol 23: 243-253.

13. Liebowitz MR, Manley AL, Padmanabhan SK, Ganguly R, Tummala R, et al. (2008) Efficacy, safety, and tolerability of desvenlafaxine $50 \mathrm{mg} /$ day and 100 $\mathrm{mg} / \mathrm{day}$ in outpatients with major depressive disorder. Curr Med Res Opin 24 1877-1890.

14. Tourian KA, Padmanabhan SK, Groark J, Brisard C, Farrington D (2009) Desvenlafaxine 50 and $100 \mathrm{mg} / \mathrm{d}$ in the treatment of major depressive disorder: an 8-week, phase III, multicenter, randomized, double-blind, placebocontrolled, parallel-group trial and a post hoc pooled analysis of three studies. Clin Ther 31: 1405-1423.

15. Shams ME, Arneth B, Hiemke C, Dragicevic A, Muller MJ, et al. (2006) CYP2D6 polymorphism and clinical effect of the antidepressant venlafaxine. J Clin Pharm Ther 31: 493-502.

16. Nichols AI, Behrle JA, Richards LS, Parker VD, Posener JA, et al. (2005) The Absolute Bioavailability of Desvenlafaxine in Healthy Subjects. J Clin Pharm Ther 77: P47-P47.
17. Dierks EA, Stams KR, Lim HK, Cornelius G, Zhang H, et al. (2001) A method for the simultaneous evaluation of the activities of seven major human drugmetabolizing cytochrome P450s using an in vitro cocktail of probe substrates and fast gradient liquid chromatography tandem mass spectrometry. Drug Metab Dispos 29: 23-29.

18. Lake BG (1987) Preparation and characterisation of microsomal fractions fo studies on xenobiotic metabolism. In: Snell K, Mullock B, eds. Biochemical toxicology: a practical approach. IRL Press, Oxford, United Kingdom; 183-215.

19. Bradford MM (1976) A rapid and sensitive method for the quantitation of microgram quantities of protein utilizing the principle of protein-dye binding Anal Biochem 72: 248-254

20. Omura T, Sato R (1964) The carbon monoxide-binding pigment of liver microsomes. I. Evidence for its hemoprotein nature. J Biol Chem 239: 2370 2378

21. Paxil [package insert]. Research Triangle Park, NC: GlaxoSmithKline. 2010

22. Ronfeld RA, Tremaine LM, Wilner KD (1997) Pharmacokinetics of sertraline and its $\mathrm{N}$-demethyl metabolite in elderly and young male and female volunteers. Clin Pharmacokinet 32 Suppl 1: 22-30.

23. Findlay JW, Van Wyck FJ, Smith PG, Butz RF, Hinton ML, Blum MR, Schroede $\mathrm{DH}$ (1981) Pharmacokinetics of bupropion, a novel antidepressant agent following oral administration to healthy subjects. Eur J Clin Pharmacol 21: 127135

24. Lantz RJ, Gillespie TA, Rash TJ, Kuo F, Skinner M, Kuan HY, Knadler MP (2003) Metabolism, excretion, and pharmacokinetics of duloxetine in healthy human subjects. Drug Metab Dispos 31: 1142-1150.

25. Preskorn S, Patroneva A, Silman H, Jiang Q, Isler JA, et al. (2009) Comparison of the pharmacokinetics of venlafaxine extended release and desvenlafaxine in extensive and poor cytochrome P450 2D6 metabolizers. J Clin Psychopharmacol 29: 39-43.

26. Nichols Al, Abell MW, Mako B, Baird-Bellaire S, Behrle JA, Posener J, Patat A, Paul J. An evaluation of the potential of cytochrome P450 3A4-mediated drug-drug interactions with desvenlafaxine use. Drug Metab Dispos In press.

27. Nichols AI, Richards LS, Behrle JA, Posener JA, McGrory SB, et al. (2011) The pharmacokinetics and safety of desvenlafaxine in subjects with chronic renal impairment. Int J Clin Pharmacol Ther 49: 3-13.

28. Oganesian A, Shilling AD, Young-Sciame R, Tran J, Watanyar A, et al. (2009) Desvenlafaxine and venlafaxine exert minimal in vitro inhibition of human cytochrome p450 and p-glycoprotein activities. Psychopharmacol Bull 42: 4763.

29. Preskorn SH, Nichols Al, Paul J, Patroneva AL, Helzner EC, et al. (2008) Effect of desvenlafaxine on the cytochrome P450 2D6 enzyme system. J Psychiatr Pract 14: 368-378.

30. Silkey B, Preskorn SH, Golbeck A, Shah R, Neff M, et al. (2005) Complexity of medication use in the Veterans Affairs healthcare system: part II. Antidepressant use among younger and older outpatients. J Psychiatr Pract 11: 16-26. 